\title{
The WSU Model for Engineering Mathematics Education
}

\author{
Klingbeil, N.W., Mercer, R.E., Rattan, K.S., Raymer, M.L. and Reynolds, D.B. \\ Wright State University, Dayton, OH, 45435
}

\begin{abstract}
This paper summarizes progress to date on the WSU model for engineering mathematics education, an NSF funded curriculum reform initiative at Wright State University. The WSU model seeks to increase student retention, motivation and success in engineering through application-driven, just-in-time engineering math instruction. The WSU approach begins with the development of a novel freshman-level engineering mathematics course (EGR 101). Taught by engineering faculty, the course includes lecture, laboratory and recitation components. Using an application-oriented, hands-on approach, the course addresses only the salient math topics actually used in a variety of core engineering courses. These include the traditional physics, engineering mechanics, electric circuits and computer programming sequences. The EGR 101 course replaces traditional math prerequisite requirements for the above core courses, so that students can advance in the engineering curriculum without having completed a traditional freshman calculus sequence. This has enabled a significant restructuring of the engineering curriculum, including the placement of formerly sophomore-level engineering courses within the freshman year. The WSU model concludes with the development of a revised engineering mathematics sequence, to be taught by the math department later in the curriculum. The result has shifted the traditional emphasis on math prerequisite requirements to an emphasis on engineering motivation for math, with a just-in-time placement of the new math sequence. The current paper summarizes the motivation, goals and development to date of the WSU model, which is currently in its first year of implementation. The paper reflects modifications since the approach was first reported one year ago, and includes a preliminary assessment of student performance and perception during the first run of EGR 101.
\end{abstract}

\section{Introduction}

The traditional approach to engineering mathematics education begins with one year of freshman calculus as a prerequisite to subsequent core engineering courses. However, only about $42 \%$ of incoming freshmen who wish to pursue an engineering or computer science degree at Wright State University (WSU) ever complete the required calculus sequence. The remaining $58 \%$ either switch majors or leave the University. This problem is not unique to WSU; indeed, the inability of incoming students to successfully advance through the traditional freshman calculus sequence plagues engineering programs across the country.

A 1998 U.S. Department of Education report ${ }^{1}$ has summarized the percent of college students who completed bachelor's degrees by age 30 in their intended fields, as indicated upon graduation from high school. In the combined fields of Engineering/Architecture, only 54\% of men and $21.3 \%$ of women were ultimately successful. While more uniform among the sexes, the numbers in the combined fields of Computer Science/Mathematics are also discouraging, with 
success rates of only $38.5 \%$ for men and $32.7 \%$ for women. On the other hand, students wishing to pursue a bachelor's degree in business exhibited success rates of $71.8 \%$ for men and $63.7 \%$ for women.

Clearly, there are a variety of factors influencing student retention and success in engineering, the most notable being a lack of preparation in high school. Moreover, engineering retention is of particular concern among members of traditionally underrepresented groups, as well as among transfer students and nontraditional students returning to school from the workplace. This has led engineering educators to introduce early intervention programs, aimed at increasing retention among incoming students ${ }^{2,3}$. The WrightSTEPP and Academic Advantage programs here at WSU are two such programs, which begin intervention with local high school students even before they begin their freshman years.

In addition to early intervention programs, there has been a strong emphasis in recent years on increasing the level of engineering application early in the curriculum, with the goal of increasing student motivation to study engineering. This has led to the development of problembased freshman engineering courses ${ }^{2,4-9}$, including the EGR 190 Fundamentals of Engineering course here at WSU. Such courses are typically designed to give students a broad, applicationbased introduction to the various engineering disciplines, so that they can begin to appreciate why they must endure the rigor of their subsequent engineering curricula. As might be expected, this can have a significant impact on early retention of incoming students. For example, researchers at Indiana University-Purdue University Fort Wayne have recently published quantitative data directly relating increased retention to enrollment in their ETCS 101 Introduction to Engineering, Technology and Computer Science course ${ }^{2}$.

Without a doubt, the introduction of early intervention programs and application-oriented freshman engineering courses are significant steps toward increasing student retention, motivation and success in engineering. That said, the correlation between retention rates and the inability of incoming students to progress through the required calculus sequence cannot be ignored. This problem is not unique to WSU, and in recent years has received substantial attention in the engineering education literature ${ }^{10-16}$. The general consensus thus far is that the traditional approach of teaching students the required mathematical theory simply as a prerequisite to subsequent engineering application is unsatisfactory, and that a more integrated approach is required. Such integration has typically been achieved by injecting engineering application into the freshman calculus sequence, sometimes in concert with a freshman engineering course.

While integrating engineering application into the freshman calculus sequence is a step in the right direction, it is proposed herein that a more radical approach is required, involving a large-scale restructuring of the engineering curriculum.

The WSU model begins with the development of a freshman-level engineering mathematics course (EGR 101). Taught by engineering faculty, the course includes lecture, laboratory and recitation components. Using an application-oriented, hands-on approach, EGR 101 addresses only the salient math topics actually used in a variety of core engineering courses. These include the traditional physics, engineering mechanics, electric circuits and computer 
programming sequences. The EGR 101 course replaces traditional math prerequisite requirements for the above core courses, so that students can advance in the engineering curriculum without having completed a traditional freshman calculus sequence. This has enabled a significant restructuring of the engineering curriculum, including the placement of formerly sophomore-level engineering within the freshman year. The WSU model concludes with the development of an engineering calculus sequence, to be taught by the math department later in the curriculum. The result has shifted the traditional emphasis on math prerequisite requirements to an emphasis on engineering motivation for math, with a just-in-time placement of the new math sequence.

The current paper summarizes the development to date of the WSU model for engineering mathematics education, which is currently in its first year of implementation. The paper reflects modifications since the approach was first reported one year ago ${ }^{17}$, and includes a preliminary assessment of student performance and perception during the first run of EGR 101.

\section{EGR 101: Introductory Mathematics for Engineering Applications}

The WSU model begins with the development of EGR 101, "Introductory Mathematics for Engineering Applications," a novel freshman-level engineering mathematics course. The goal of EGR 101 is to address only the salient mathematics topics actually used in the primary core engineering courses, thereby fulfilling math prerequisite requirements within the context of a single course. This has opened the door for students to advance in the engineering curriculum without first completing the traditional calculus sequence.

The content of EGR 101 consists of the mathematical prerequisites for the following core engineering courses: PHY 240 (General Physics I), ME 212 (Statics), ME 213 (Dynamics), ME 313 (Strength of Materials), EE 301 (Circuit Analysis I), CEG 220 (C Programming), and EGR 153 (Fortran Programming). In the traditional curriculum, all of these courses require a minimum of Calculus I, while some require Calculus I-III and Differential Equations. Clearly, it is impossible to cover all topics in Calculus I-III and Differential Equations within a single course, let alone a freshman course. However, only a handful of these topics are actually applied in the above core engineering courses. Moreover, the above core courses also include engineering mathematics concepts not found in the traditional calculus sequence, including basic operations in vectors, complex numbers and matrix algebra.

After consultation with faculty from around the College, the following math topics were slated for inclusion in EGR 101: Basic Algebraic Manipulations; Trigonometry; 2-D Vectors; Complex Numbers; Sinusoids and Harmonic Signals; Systems of Equations and Matrices; Basics of Differentiation; Basics of Integration; Linear Differential Equations with Constant Coefficients. The course structure is 5 credit hours ( 4 hours lecture, 1 hour lab), plus mandatory recitation sections. The course is taught by engineering faculty, with all mathematical topics motivated by their direct application in the core engineering courses. Moreover, course material is emphasized by physical experiments in the classroom and laboratory, and is thoroughly integrated with the engineering analysis software MATLAB.

A detailed outline of the EGR 101 course content over a period of one 10 week quarter is outlined in Table 1 below: 
Table 1. EGR 101 Course Outline

\begin{tabular}{|c|c|}
\hline & \\
\hline $\begin{array}{l}\text { Lecture: Course Introduction ( } 1 \text { hour); } \\
\text { Application of Algebra in Engineering - Linear } \\
\text { Equations ( } 1.5 \text { hours); Application of Algebra in } \\
\text { Engineering - Quadratic Equations (1.5 hours) } \\
\text { Lab: Introduction to MATLAB }\end{array}$ & $\begin{array}{l}\text { Lecture: Trigonometry - One-Link Planar Robot } \\
\text { (2 hours); Trigonometry - Two-Link Planar Robots } \\
\text { (2 hours) } \\
\text { Lab: Application of Algebra in Engineering: The } \\
\text { One-Loop Circuit }\end{array}$ \\
\hline $\begin{array}{l}\frac{\text { Week } \mathbf{3}}{\text { Lecture: }} \\
\text { Complex Numbers in Engineering ( } 2 \text { hours); } \\
\text { Lab: Measurement of Trigonometric Relationships } \\
\text { in One and Two-Link Planar Robots }\end{array}$ & $\begin{array}{l}\text { Week } 4 \\
\text { Eecture: Sinusoids and Harmonic Signals in } \\
\text { Engineering ( } 2 \text { hours); Systems of Equations in } \\
\text { Engineering ( } 2 \text { hours) } \\
\text { Lab: Measurement and Analysis of Harmonic } \\
\text { Signals }\end{array}$ \\
\hline $\begin{array}{l}\text { Lecture: Introduction to Derivatives in } \\
\text { Engineering ( } 2 \text { hours); Application of Derivatives - } \\
\text { Velocity and Acceleration ( } 2 \text { hours) } \\
\text { Lab: Systems of Equations in Engineering: The } \\
\text { Two-Loop Circuit }\end{array}$ & $\begin{array}{l}\text { Lecture: Application of Derivatives - Electric } \\
\text { Circuits }(2 \text { hours); Application of Derivatives - } \\
\text { Deflection of Beams ( } 2 \text { hours) } \\
\frac{\text { Lab: Derivatives in Engineering: Velocity and }}{\text { Acceleration in Free-Fall }}\end{array}$ \\
\hline $\begin{array}{l}\text { Lecture: Introduction to Integrals in Engineering } \\
\text { (2 hours); Application of Integrals in Statics }(2 \\
\text { hours); } \\
\text { Lab: Integrals in Engineering: Work and Stored } \\
\text { Energy in a Spring }\end{array}$ & $\begin{array}{l}\text { Lecture: Application of Integrals in Dynamics }(2 \\
\text { hours); Application of Integrals in Electric Circuits } \\
\text { ( } 2 \text { hours) } \\
\frac{\text { Lab: }}{\text { Leaking Bucket }}\end{array}$ \\
\hline $\begin{array}{l}\text { Lecture: Introduction to Differential Equations: } \\
\text { The Leaking Bucket ( } 2 \text { hours); Application of } \\
\text { Differential Equations - Mechanical Systems ( } 2 \\
\text { hours) } \\
\text { Lab: Differential Equations in Engineering: } \\
\text { Spring-Mass Vibration }\end{array}$ & $\begin{array}{l}\text { Lecture: Application of Differential Equations - } \\
\text { Electrical Systems ( } 2 \text { hours); Catch-up, Summary } \\
\text { and Review ( } 2 \text { hours) } \\
\underline{\text { Lab: }} \text { : Make-up laboratory session }\end{array}$ \\
\hline
\end{tabular}

Note that in the above course outline, all math topics are presented within the context of their engineering application, and reinforced through hands-on laboratory assignments. However, unlike typical engineering laboratory assignments, which are designed to illustrate engineering physics, all EGR 101 laboratory assignments are designed to illustrate engineering mathematics. Indeed, physical measurement of the derivative as the velocity in free-fall (Week 6 ), or of the integral as the area under the force-deflection curve (Week 7), provides a much greater conceptual understanding of the mathematical concepts than classroom lecture alone. In 
addition, all laboratory data is processed with MATLAB, so that the students can immediately appreciate the interconnection between classroom theory, laboratory measurement and numerical representation of their engineering results.

The prerequisite requirement for incoming students to register for EGR 101 is a minimum mathematics background in Trigonometry, as indicated by a combination of math placement scores and high school transcripts, or by the completion of MTH 131 (Trigonometry) at WSU. Of the 300 incoming freshmen typically arriving each year, it is estimated that roughly one-third will satisfy the prerequisite requirements immediately in the Fall quarter. However, it is anticipated that EGR 101 will run every quarter, so that the remaining students can register immediately upon completion of the necessary prerequisite mathematics background.

\section{Restructured Engineering Curriculum}

The primary goal of EGR 101 is to facilitate a large-scale restructuring of the engineering curriculum, where students can advance in the program without having completed a traditional freshman calculus sequence.

In order to emphasize the need for the proposed curriculum changes, the traditional freshman year curriculum for Mechanical Engineering is shown in Table 2. In order to advance into their sophomore years, students are expected to complete MTH 229 Calc I, MTH 230 Calc II and MTH 231 Calc III during their first three quarters at the University. This is the case for the remainder of engineering majors in the College, and is standard practice in engineering programs across the country. No wonder students who struggle in calculus end up switching majors!

Table 2. Traditional Freshman Year (Mechanical Engineering)

\begin{tabular}{|l|l|l|l|l|l|}
\hline \multicolumn{2}{|c|}{ Fall Quarter } & \multicolumn{2}{c|}{ Winter Quarter } & \multicolumn{2}{c|}{ Spring Quarter } \\
\hline ENG 101 & 4 & ENG 102 & 4 & ME 199 & 3 \\
\hline EGR 190 & 4 & EGR 153/CEG 220 & 4 & PHY 240 & 5 \\
\hline CHM 121 & 5 & GE & 4 & GE & 4 \\
\hline MTH 229 Calc I $^{*}$ & 5 & MTH 230 Calc II & 5 & MTH 231 Calc III & 5 \\
\hline & 18 & & 17 & & 17 \\
\hline
\end{tabular}

* Traditional freshman calculus sequence

It is proposed herein that by structuring the curriculum in the traditional fashion, we are effectively telling those students who struggle in calculus that they are not cut out to be engineers, and should find another major!

The restructured alternative to the traditional freshman year curriculum is shown in Table 3. The EGR 101 course appears immediately in the Fall quarter. However, as previously noted, the course is scheduled to run every quarter, so that those students who do not immediately qualify for EGR 101 can register as soon as they complete the necessary math background (trigonometry). 
In addition to the presence of EGR 101, the new freshman year curriculum has a number of features which distinguish it from the traditional curriculum of Table 2. Most notably, the only Math department course in the freshman year is MTH 229 Calc I. This is the first course in the revised engineering calculus sequence, which now has separate sections designated for engineers. It should be noted that because EGR 101 will be the only math prerequisite for core sophomore year engineering courses, students who are not immediately successful in MTH 229 Calc I can still advance in the program.

Table 3. Restructured Freshman Year (Mechanical Engineering)

\begin{tabular}{|l|l|l|l|l|l|}
\hline \multicolumn{2}{|c|}{ Fall Quarter } & \multicolumn{2}{c|}{ Winter Quarter } & \multicolumn{2}{c|}{ Spring Quarter } \\
\hline ENG 101 & 4 & ENG 102 & 4 & ME 199 & 3 \\
\hline EGR 190 & 4 & EGR 153/CEG 220 & 4 & PHY 240 & 5 \\
\hline CHM 121 & 5 & MTH 229 Calc I ${ }^{* *}$ & 5 & GE & 4 \\
\hline EGR 101 & 5 & ME 220 & 3 & ME 202 & 4 \\
\hline & 18 & & 16 & & 16 \\
\hline
\end{tabular}

* New freshman engineering mathematics course

** First course in the revised engineering calculus sequence, with separate sections for engineers.

Another key feature of the revised curriculum is the presence of formerly sophomorelevel courses in the freshman year. In place of MTH 230 and 231 (the traditional Calc II and Calc III courses), both ME 220 Introduction to Manufacturing Processes and ME 202 Engineering Graphics have been moved to the freshman year. These are hands-on, applicationoriented engineering courses which will go a long way toward making incoming students feel like they are actually doing engineering. This is in contrast to the traditional freshman calculus sequence, which effectively precludes all too many students from exposure to sophomore-level engineering courses.

While Tables 2 and 3 are specific to Mechanical Engineering, similar changes have been made for degree programs across the College. To date, restructured program guides have been developed for Mechanical Engineering, Materials Science and Engineering, Electrical Engineering, Engineering Physics, Biomedical Engineering, and Industrial and Systems Engineering. Each of these follows the freshman year model of Table 3, including the introduction of EGR 101, the removal of the second and third calculus courses from the freshman year, and the introduction of formerly sophomore-level engineering courses within the freshman year (as appropriate). As discussed in the next section, the just-in-time placement of the new engineering math sequence affects program guides for most majors in the College all the way through the first quarter of junior year.

While the restructured curriculum is now recommended to all incoming students, it still provides a measure of flexibility with regard to the math sequence. For example, those students who might prefer to take MTH 229 Calc I and MTH 230 Calc II in immediate succession can still do so by taking MTH 230 in lieu of the GE course during the Spring quarter of freshman year. The GE requirement can always be made up later in the curriculum. Indeed, the restructured curriculum is intended to open the door for those students who might otherwise fall behind - not close the door to those students who might wish to get ahead! 
Finally, revised math prerequisite requirements for the core engineering and physics courses previously summarized have been submitted and approved by the University. In all cases, the words "or EGR 101" have been appended to the traditional math prerequisite requirements. This automatically accounts for transfer and continuing students, who can advance in the program with either the traditional math sequence or the completion of EGR 101.

\section{Development of Revised Engineering Math Sequence}

While EGR 101 provides an introduction to the salient math topics required to progress in the engineering curriculum, it is not intended to be a replacement for the calculus sequence and other subsequent mathematics courses. The traditional calculus sequence at WSU consists of four quarters of calculus: MTH 229 Calc I, MTH 230 Calc II, MTH 231 Calc III, and MTH 232 Calc IV. Each of these courses is 5 credit hours, including 4 hours lecture and 1 hour lab. In addition to this four quarter calculus sequence, the majority of majors in the College of Engineering and Computer Science have traditionally required a 5 credit hour course in Differential Equations, as well as a 3 credit hour course in Matrix Algebra.

In order to accommodate EGR 101, the various engineering departments have been required to free up additional credit hours in their respective degree programs. Towards this goal, it was initially proposed to streamline the existing calculus sequence into three quarters, with greater emphasis on engineering application. However, there was significant concern among members of the Department of Mathematics and Statistics that streamlining the calculus sequence cannot be done without jeopardizing student learning, including the development of problem solving skills so critical to engineering.

In light of these concerns, the revised engineering calculus sequence is to remain four quarters long, but with separate sections designated for engineering students (where possible), and with a greater emphasis on engineering application. As previously described, Calc I is part of the freshman curriculum, with the remaining courses delayed until the sophomore and junior years. The exact locations of the remaining courses are specific to each major in the College, as determined at the department level. In Mechanical Engineering, the revised Calc II and III courses will occur in the sophomore year, while Calc IV will be reserved for the first quarter of junior year. In addition, the traditional Differential Equations and Matrix Algebra courses will be combined into a single 5-hour course, "MTH 235 Differential Equations with Matrix Algebra," to be offered during the sophomore year beginning Spring, 2005.

Coupled with the restructured program guides previously described, the result of the new math sequence is a more just-in-time, application oriented approach to engineering mathematics. Compared to the traditional freshman calculus sequence, the benefits of such an approach are many. In the restructured curriculum, advanced math concepts will be presented much closer to the time they are needed in the engineering curriculum. For example, while advanced concepts in calculus (e.g., the Divergence Theorem) are traditionally presented in the late freshman or early sophomore years, the application of such concepts in the engineering curriculum is typically not encountered until the junior or senior years. As a result, students can lose the connection between the mathematical theory and its relevant engineering application, which can result in a decreased motivation to study math. In contrast, the just-in-time structure of the 
revised math sequence will reinforce the students' motivation to study both math and engineering. Moreover, with the revised math sequence offered later in the curriculum, the students enrolled in calculus will be more mature, and will benefit from the problem solving skills already developed in their entry-level core engineering courses.

\section{Preliminary Assessment - Results of EGR 101 First Run}

Prior to the first run of EGR 101, there were some questions among both math and engineering faculty surrounding the feasibility of the course. Namely, would it really be possible to cover all the salient math topics required for core sophomore-level engineering courses within the context of a single course, let alone a freshman course? Would the breadth of engineering and mathematics content outlined in Table 1 prove overwhelming for the students, and ultimately have a detrimental effect on first-year retention? Finally, would the EGR 101 course really increase the students' motivation and chances of success in both math and engineering? While the previously reported pilot study ${ }^{17}$ was encouraging, such questions could ultimately be addressed only by running the course.

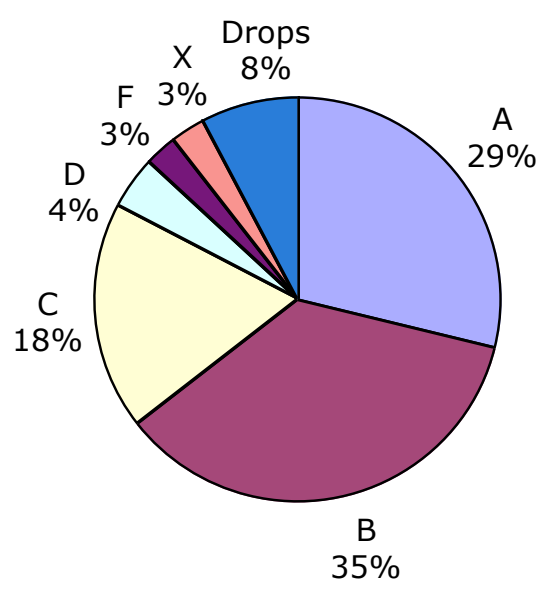

\section{Figure 1. Student Performance in EGR 101 First-Run}

The EGR 101 course ran for the first time in the Fall quarter of 2004, following the course outline of Table 1. Nearly all eligible incoming freshmen in Mechanical Engineering, Materials Science and Engineering, Industrial Engineering, Biomedical Engineering, Electrical Engineering and Engineering Physics were enrolled in the course. The total enrollment was 76 students, who were divided between 2 lecture sections, 6 laboratory sections and 9 recitation sections. The lecture sections were administered by the authors N. Klingbeil and K. Rattan, while the laboratory and recitation sections were staffed by a total of 5 graduate teaching assistants. Student performance was assessed through graded homework and labs, block midterm exams in weeks 5 and 8, and a block final exam following week 10. Final grades were administered according to a standard University scale (A: 90-100, B: 80-89, C: 70-79, D: 6069, F: <60), with minor adjustments for borderline cases.

The final grade distribution for the first run of EGR 101 is shown in Figure 1. In short, student performance was extremely encouraging. Of the 76 students enrolled, over $80 \%$ completed the course with a grade of " $C$ " or better. This includes those students who either dropped or failed to complete the course (grade of " $\mathrm{X}$ " in Fig. 1). While first year retention can

Proceedings of the 2005 American Society for Engineering Education Annual Conference \& Exposition Copyright (C) 2005, American Society for Engineering Education 
only be assessed following the close of the academic year, this suggests the potential for a dramatic improvement over the $42 \%$ of engineering students who have traditionally advanced past the freshman calculus sequence at WSU.

It should be noted that the first-run of EGR 101 included only those incoming students who were immediately eligible for the course, many of whom had prior exposure to calculus in high school. As such, it is of interest to compare student performance when sorted by high school math background. Such a comparison is depicted in Figure 2, which shows the final grade distribution among those students with at least some calculus in high school (Fig. 2a), compared to the final grade distribution among those students without (Fig. 2b). Since high school math background was determined by student survey at the end of the course, the data of Fig. 2 does not include students who dropped or failed to complete the course.

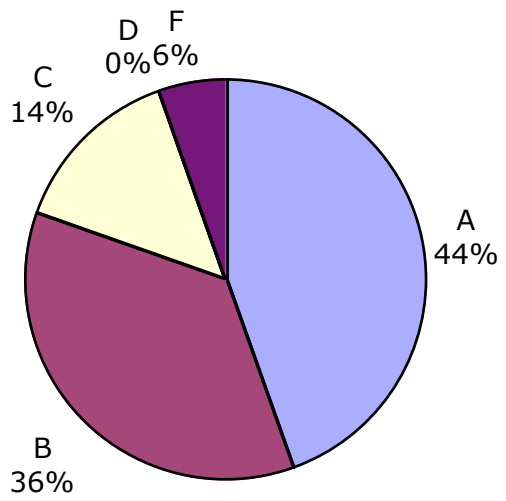

a)

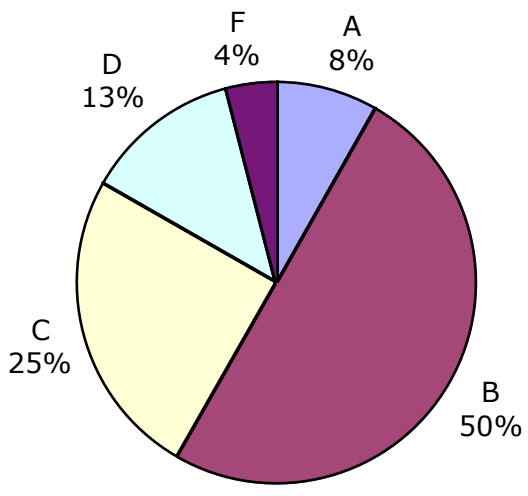

b)

Figure 2. Performance of Students Completing EGR 101

(a) With Calculus in High School and (b) Without Calculus in High School

As might be expected, those students who had at least some calculus in high school had a significant advantage in EGR 101, with $80 \%$ earning an "A" or "B", and 94\% earning a grade of "C" or better. It is unclear whether or not this advantage is due to the calculus background itself, or the fact that those students who take advanced mathematics in high school simply tend to be better students. That said, the results of Fig. $2 \mathrm{~b}$ are extremely encouraging in their own right. Of those students without calculus in high school, 58\% earned at least a "B" in EGR 101, and 83\% earned a grade of "C" or better. Such results seem to confirm that even students with no prior calculus background can digest and apply mathematics concepts spanning calculus through differential equations, when presented in the context of their engineering application.

In addition to student performance, a preliminary assessment of student perception was obtained through surveys distributed at the end of the course. Specifically, students were asked whether EGR 101 had increased their motivation to study math and engineering, and whether EGR 101 had increased their chances of success in future math and engineering courses. Answers were given on a scale of 1 (strongly disagree) to 5 (strongly agree), with 3 being neutral. 
The results of the student survey, as sorted by high school math background, are shown in Figure 3. On average, student perception of EGR 101 was very encouraging, with both groups of students reporting an increased motivation to study both math and engineering, as well as an increased chance of success in future math and engineering courses. Although students with calculus in high school had a significant advantage in performance, there was little difference in perception between the two groups. Interestingly, students with no calculus in high school actually had a slightly stronger perception of EGR 101 in three of the four categories. The strongest perception reported by both groups of students was that EGR 101 had increased their chance of success in future math courses, which is anticipated to have a significant effect on student retention through the revised math sequence.

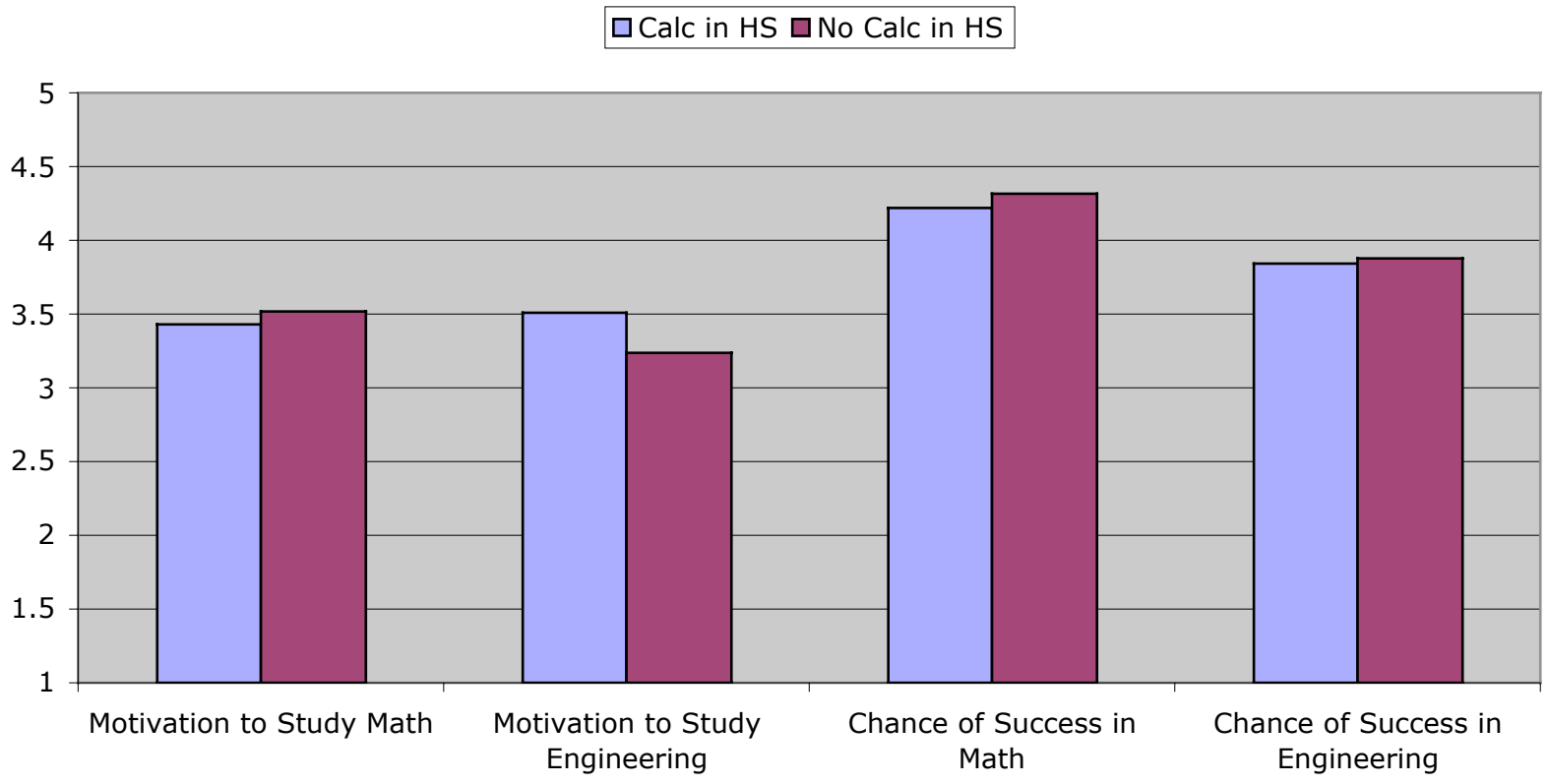

Figure 3. Student Perception of EGR 101 Sorted by High School Math Background

Results of the student survey sorted by EGR 101 grade are shown in Figure 4. Clearly, there was a strong link between student performance and their perception of EGR 101. Students earning an "A" in EGR 101 had the strongest perception of the course, while the perceived benefits of EGR 101 declined monotonically with student performance. In particular, students achieving grades of "C" and below did not generally agree that EGR 101 had increased their motivation to study engineering. However, those same students did agree that EGR 101 had increased their chance of success in both math and engineering courses, which will hopefully help offset their lack of motivation. Finally, it does appear that EGR 101 had a significant impact on both motivation and perceived chance of success for students earning at least a " $\mathrm{B}$ " in the course, who comprised $64 \%$ of the initial enrollment. It is anticipated that this increase in student motivation and confidence will contribute to increased retention in the months and years to come. 


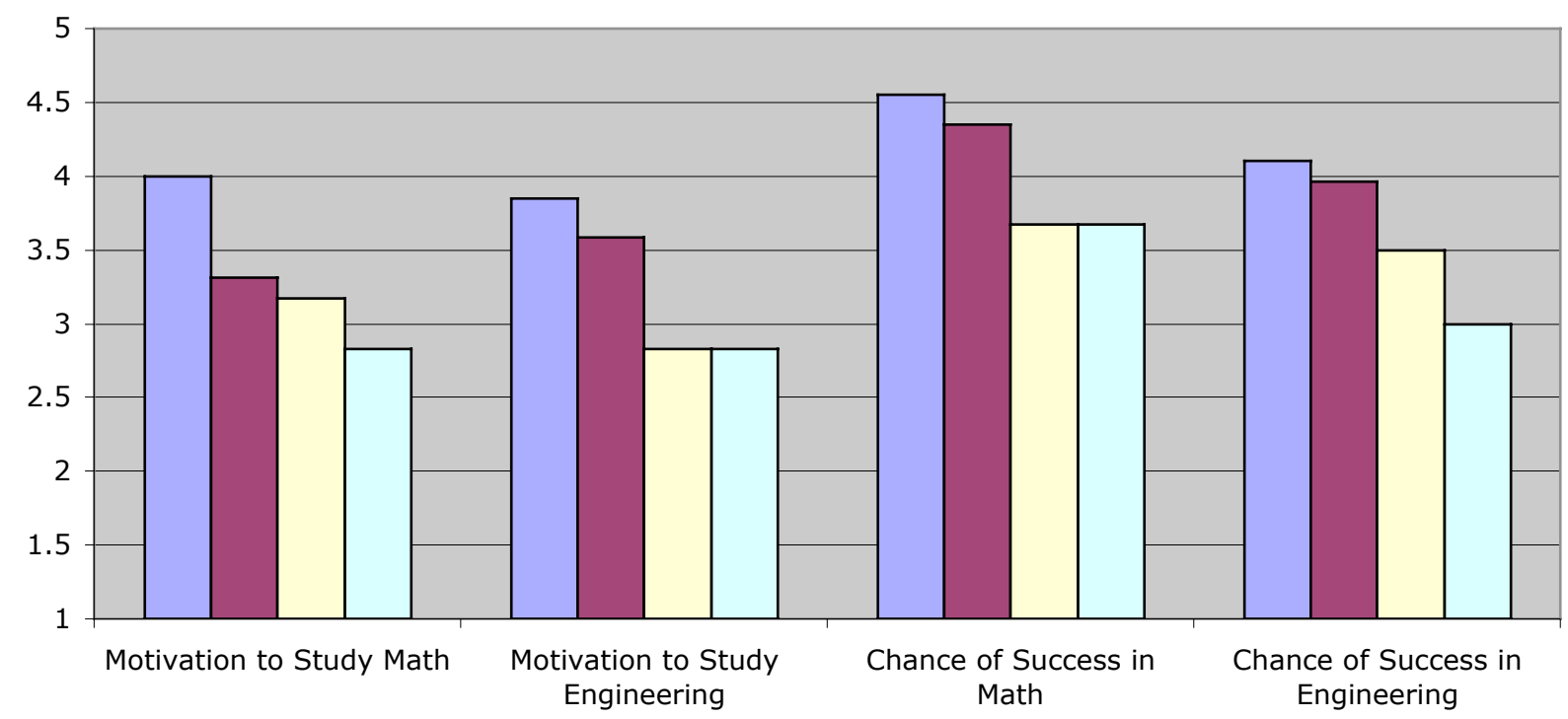

Figure 4. Student Perception Sorted by Grade in EGR 101

\section{Conclusions}

This paper has summarized the WSU model for engineering mathematics education, an NSF supported curriculum reform initiative at Wright State University. The WSU model seeks to increase student retention, motivation and success in engineering through application-driven, just-in-time engineering math instruction. The approach involves the development of a novel freshman engineering mathematics course EGR 101, as well as a large-scale restructuring of the engineering curriculum. Student performance in the first run of EGR 101 has confirmed the feasibility of the course, with over $80 \%$ of the initial enrollment completing the course with a grade of "C" or better. Student perception following the first run of EGR 101 was also encouraging. On average, students confirmed that EGR 101 had increased their motivation to study both math and engineering, as well as their chance of success in future math and engineering courses. The ultimate effect of EGR 101 and the restructured engineering curriculum on student retention and success in core courses remains to be seen, and will be closely studied in the months and years to come.

\section{Acknowledgements}

This work has been supported by a planning grant from the National Science Foundation, Division of Engineering Education and Centers, under program solicitation NSF-03-562, "Department Level Reform of Undergraduate Engineering Education," Grant Number EEC0343214. This work has also been supported by the College of Engineering \& Computer Science and the Department of Mathematics \& Statistics at Wright State University.

\section{Bibliography}

1. Adelman, Clifford, 1998, "Women and Men of the Engineering Path: A Model for Analyses of Undergraduate Careers," U.S. Department of Education Report, May, 1998.

2. Pomalaza-Raez, C. and Henry Groff, B., 2003, "Retention 101: Where Robots Go... Students Follow," Journal of Engineering Education, Vol. 92, No. 1, 85-90. 
3. Arenaz, P., Fisher, W., Della-Piana, C. K., 1999, "CircLES: A Retention Program for Entering Students in Engineering, Mathematics and Science," Proceedings - Frontiers in Education Conference, Vol. 3, 13d8-2.

4. Richardson, J., Dantzler, J, 2002, "Effect of a Freshman Engineering Program on Retention and Academic Performance," Proceedings - Frontiers in Education Conference, Vol. 3, S2C/16-S2C/22.

5. Kellar, J.J., Hovey, W., Langerman, M., Howard, S., Simonson, L., Kjerengtroen, L., Stetler, L., Heilhecker, H., Arneson-Meyer, L., Kellogg, S. D., 2000, "Problem Based Learning Approach for Freshman Engineering," Proceedings - Frontiers in Education Conference, Vol. 2, F2G-7-F2G-10.

6. Howard, B., 1999, "Enough of This Science and Mathematics, Let's Do Some Engineering," Proceedings Frontiers in Education Conference, Vol. 3, 13d2-8.

7. Clausing, A.M., 1998, "Successful Freshman Engineering Course: An Active Learning Experience," ASEE Annual Conference Proceedings, 1998.

8. Corradini, M.; Farrell, P.; Mitchell, J.; Marleau, R.; Moskwa, J.; Sanders, K.; Webster, J., 1995, "Team-Based Design Course for Freshmen," ASEE Annual Conference Proceedings, Vol. 2, 2044-2053.

9. Dally, J. W. and Zhang, G. M., 1993, "Freshman Engineering Design Course," Journal of Engineering Education, Vol. 82, No. 2, 83-91.

10. Guzdial, M., Ludovice, P., Realff, M., Morley, T., Carroll, K., Ladak, A., 2001, "The Challenge of Collaborative Learning in Engineering and Math," Proceedings - Frontiers in Education Conference, Vol. 1, $\mathrm{T} 3 \mathrm{~B} / 24-\mathrm{T} 3 \mathrm{~B} / 29$.

11. McKenna, A., McMartin, F. and Agogino, A., 2000, "What Students Say About Learning Physics, Math and Engineering," Proceedings - Frontiers in Education Conference, Vol. 1, T1F-9.

12. Sathianathan, D., Tavener, S., Voss, K. Armentrout, S. Yaeger, P. and Marra, R., 1999, "Using Applied Engineering Problems in Calculus Classes to Promote Learning in Context and Teamwork," Proceedings Frontiers in Education Conference, Vol. 2, 12d5-14.

13. Barrow, D.L. and Fulling, S.A., 1998, "Using an Integrated Engineering Curriculum to Improve Freshman Calculus," Proceedings of the 1998 ASEE Conference, Seattle, WA.

14. Hansen, E.W., 1998, "Integrated Mathematics and Physical Science (IMPS): A New Approach for First Year Students at Dartmouth College," Proceedings - Frontiers in Education Conference, Vol. 2, 579.

15. Kumar, S. and Jalkio, J., 1998, "Teaching Mathematics from an Applications Perspective," Proceedings of the 1998 ASEE Conference, Seattle, WA.

16. Whiteacre, M.M. and Malave, C.O., 1998, "Integrated Freshman Engineering Curriculum for Pre-Calculus Students," Proceedings - Frontiers in Education Conference, Vol. 2, 820-823.

17. Klingbeil, N.W., Mercer, R.E., Rattan, K.S., Raymer, M.L. and Reynolds, D.B., 2004, "Rethinking Engineering Mathematics Education: A Model for Increased Retention, Motivation and Success in Engineering," ASEE Annual Conference Proceedings, Salt Lake City, Utah, June 2004, pp. 12169-12180. 


\section{Biographical Information}

NATHAN W. KLINGBEIL is an Associate Professor in the Department of Mechanical \& Materials Engineering at Wright State University. He received his Ph.D. in Mechanical Engineering from Carnegie Mellon University in 1998. Professor Klingbeil is currently leading NSF supported research projects in the areas of manufacturing science and engineering curriculum reform. He is the recipient of several awards for his work in engineering education, including the ASEE North Central Section Outstanding Teacher Award (2004), and both the CECS Excellence in Teaching (2002) and Excellence in Professional Service (2004) awards at Wright State University.

RICHARD E. MERCER is an Associate Professor in the Department of Mathematics and Statistics at Wright State University. He received his Ph.D. in Mathematics from the University of Washington in 1980. Professor Mercer is active in curriculum reform, and has led an NSF supported effort to integrate Mathematica laboratory sessions into the freshman calculus sequence at Wright State University.

KULDIP S. RATTAN is a Professor in the Department of Electrical Engineering at Wright State University. He received his Ph.D. in Electrical Engineering from the University of Kentucky in 1975. Professor Rattan conducts research in the area of electrical control systems, and is active in engineering education reform. He has been the recipient of the CECS Excellence in Teaching Award at Wright State University in both 1985 and 1992, and of the CECS Excellence in Service Award in 1991, 1996 and 2003.

MICHAEL L. RAYMER is an Assistant Professor in the Department of Computer Science \& Engineering at Wright State University. He received his Ph.D. in Computer Science and Engineering from Michigan State University in 2000. Professor Raymer has led an NSF supported research project to develop the nation's first undergraduate curriculum in bioinformatics, and has been a finalist for the CECS Excellence in Teaching Award at Wright State University.

DAVID B. REYNOLDS is an Associate Professor in the Department of Biomedical, Industrial and Human Factors Engineering at Wright State University. He received his Ph.D. in Biomedical Engineering from the University of Virginia in 1978. Professor Reynolds has conducted NSF supported research to develop human factors engineering undergraduate design projects for persons with disabilities, and has been a finalist for the CECS Excellence in Teaching Award at Wright State University. 